\title{
COMPARISON OF RESULTS OF THE NORMAL BALLISTOCARDIO- GRAM AND A DIRECT FICK METHOD IN MEASURING THE CARDIAC OUTPUT IN MAN ${ }^{1}$
}

\author{
By ANDRE COURNAND, H. A. RANGES, AND R. L. RILEY \\ (From the Department of Medicine, College of Physicians and Surgeons, Columbia University; \\ the Department of Medicine, New York University College of Medicine; the Third \\ Medical Division and the Tuberculosis Service, Bellevue Hospital, New York City)
}

(Received for publication December 2, 1941)

Starr and his associates (1) have demonstrated several characteristics of the ballistocardiographic method of cardiac output determination which recommend it for clinical use. The technique is simple, the apparatus is highly sensitive to small variations in stroke volume, the results in the same individual are consistent, and the limits of normality are well defined. The usefulness of the method for investigative work, however, depends in addition upon its degree of accuracy.

Preliminary information as to the accuracy of the method has been provided by Starr et al. by comparing results calculated from the ballistocardiogram with those obtained by other methods of cardiac output determination. Almost simultaneous cardiac output determinations by both the ethyl iodide method and the ballistocardiograph were performed on 30 subjects (2). Of these, the 25 best cases showed values of cardiac output averaging 3.9 per cent smaller by the ballistocardiograph than by the ethyl iodide method.

A larger discrepancy was found between a group of 106 normal subjects studied by the ballistocardiograph (1) and two other groups of normal subjects studied by the ethyl iodide (3) and acetylene methods (4). Values for cardiac output by the ballistocardiograph averaged 14.4 per cent smaller than by the ethyl iodide method and 13.6 per cent smaller than by the acetylene method. It must be noted in addition that standard basal conditions were not obtained in the group studied with the ballistocardiograph. If more rigid basal conditions had prevailed as in the two series studied by the foreign gas methods, it is fair to assume that the figures for cardiac output by the ballistocardiograph would have been somewhat lower, thus increasing the discrepancy. The comparisons presented to date do not satis-

1 Under a grant from the Commonwealth Fund. factorily evaluate the accuracy of the ballistocardiographic method and suggest the need for further data.

The present study is a comparison of cardiac output determined by a method based on the Fick principle and by the ballistocardiograph.

\section{METHOD}

The technique of cardiac output determination based on the Fick principle involved collection of mixed venous blood, arterial blood, and expired air. Mixed venous blood was withdrawn from the right auricle by means of a catheter. The method of catheterization has been described by two of the present authors (5). It was modified in individuals whose arm veins were not large enough to permit the introduction of a 10 gauge needle. In these cases the vein was exposed and the catheter introduced directly through a small slit in the vein. In order to insure that the gas concentration of the mixed venous blood remained unaltered, the samples were collected over mercury instead of under oil. The mercury sampling tube was previously prepared by introducing the anticoagulant, potassium oxalate and sodium fluoride, and allowing it to dry. Any gas trapped in the tube was removed by evacuating and expelling. Thus prepared, the tube was attached to the catheter. After interrupting the previous flow of saline, $3 \mathrm{cc}$. of blood were withdrawn through a side arm to wash out the saline, and 10 to 15 cc. of blood then drawn into the sampling tube by slight suction created by lowering the levelling bulb. This procedure required about 20 to 30 seconds. The blood was immediately mixed with the anticoagulant by inverting the sampling tube several times. Pipettes were filled directly for analysis, and any remaining blood was kept on ice under a slight positive pressure. A sample of arterial blood was taken under oil from the femoral artery, starting 15 seconds after the sampling of the mixed venous blood had begun. The expired air was collected in a Tissot spirometer, beginning 30 seconds before the mixed venous blood sampling and continuing for $1 \frac{1}{2}$ minutes. The expired air and blood samples were analyzed in duplicate for carbon dioxide and oxygen content.

The technique of obtaining mixed venous blood through a catheter in the right auricle made possible two determinations of cardiac output from each set of samples. 
The two values obtained from

Total $\mathrm{CO}_{2}$ output in cc. per minute

$\mathrm{CO}_{2}$ arteriovenous difference, cc. per liter of blood

and from

Total $\mathrm{O}_{2}$ intake, in cc. per minute

$\mathrm{O}_{2}$ arteriovenous difference, $c c$. per liter of blood

acted as independent checks upon each other.

Ballistocardiographic tracings were taken immediately before and immediately after each direct Fick determination.2 Estimates of cardiac output from ballistocardiograms were made by two independent persons. Complexes covering at least one respiratory cycle were chosen. If the influence of respiration upon the tracing varied, complexes covering several cycles were calculated. The wave area formula was used (Formula 16 in Starr's original paper (2)). Triangles were constructed by extending the sides of waves $I$ and $J$ and the areas under the waves were approximated by calculating the areas of the triangles. The altitude was measured with a divider to the half millimeter. The base of the triangle was measured from the timer lines on the tracing, the reading being accurate to within 0.04 seconds and estimated to within 0.02 seconds. At the end of each experiment the bed was calibrated and the formula corrected accordingly.

\section{RESULTS}

Thirty-one attempts in 19 different subjects were made to introduce the catheter into the right auricle. Twenty-four attempts in 18 subjects were successful. Forty-eight direct Fick determinations were attempted in these 18 subjects. Twentyone determinations in 13 subjects were satisfactory. In 5 of these 21 instances, the ballistocardiograms were discarded, either because the difference in pulse rate between determinations was too large (more than 3 beats), or because of technical error in taking the tracing. Thus in 16 instances, involving 12 patients, both direct Fick determinations and the ballistocardiograms were technically satisfactory.

All data from which cardiac output determinations by the direct Fick method were calculated are tabulated in Table $I$. The subjects were not under standard basal metabolic conditions, and several of them were not normal. The values for cardiac output can therefore only be used for comparison with those obtained by another method

2 The ballistocardiograph used was designed by Drs. Dugold E. S. Brown and Homer A. Smith on the same principle as Dr. Starr's apparatus (see appendix). employed almost simultaneously and under identical circumstances. It is of interest, however, that, after excluding subjects who had received angiotonin or had been subjected to a prolonged surgical operation, the average oxygen arteriovenous difference per $100 \mathrm{cc}$. of blood was $4.8 \mathrm{cc}$., with extremes of $4.0 \mathrm{cc}$. and $6.0 \mathrm{cc}$. This is somewhat lower than average figures obtained with the foreign gas methods in normal subjects under standard basal conditions but is well within the range of variation.

The direct Fick method as used here provides a check within itself. The respiratory quotient derived in the usual way by analysis of expired air can be checked against a respiratory quotient derived from blood gas analysis by the ratio

$\mathrm{CO}_{2}$ arteriovenous difference (volume per cent)

$\mathrm{O}_{2}$ arteriovenous difference (volume per cent)

These values are shown in Columns 4 and 11 . In only 4 determinations is the difference 0.04 or greater, being 0.04 in 2 cases, 0.06 in 1 case, and 0.07 in another.

The two figures for cardiac output, one derived from the carbon dioxide data, the other from the oxygen data, are listed in Columns 12 and 13 . In only 2 instances was the difference greater than 0.24 liters per minute, being 0.35 and 0.43 liters per minute in these cases. On an average, each determination differed by only 4.3 per cent from the mean value of the pair.

In Table II are tabulated data comparing stroke volumes determined by the direct Fick method and calculated from the ballistocardiographic tracings. The figures for the direct Fick determinations were calculated by averaging the values for cardiac output per minute calculated separately from the carbon dioxide and the oxygen data, and dividing by pulse rate; the figures for the ballistocardiographic determinations were obtained by averaging the results before and after the direct Fick. The ballistocardiograms of the first 2 cases, while apparently technically correct, showed complexes which were small and which in 1 case were irregular. Since the error in calculating cardiac output from these tracings may have been large, the cases have not been included in the final comparison of the two methods. In the remaining 14 experiments, the stroke volume by direct Fick 
TABLE I

Data obtained in 21 determinations of cardiac output by the direct Fick method

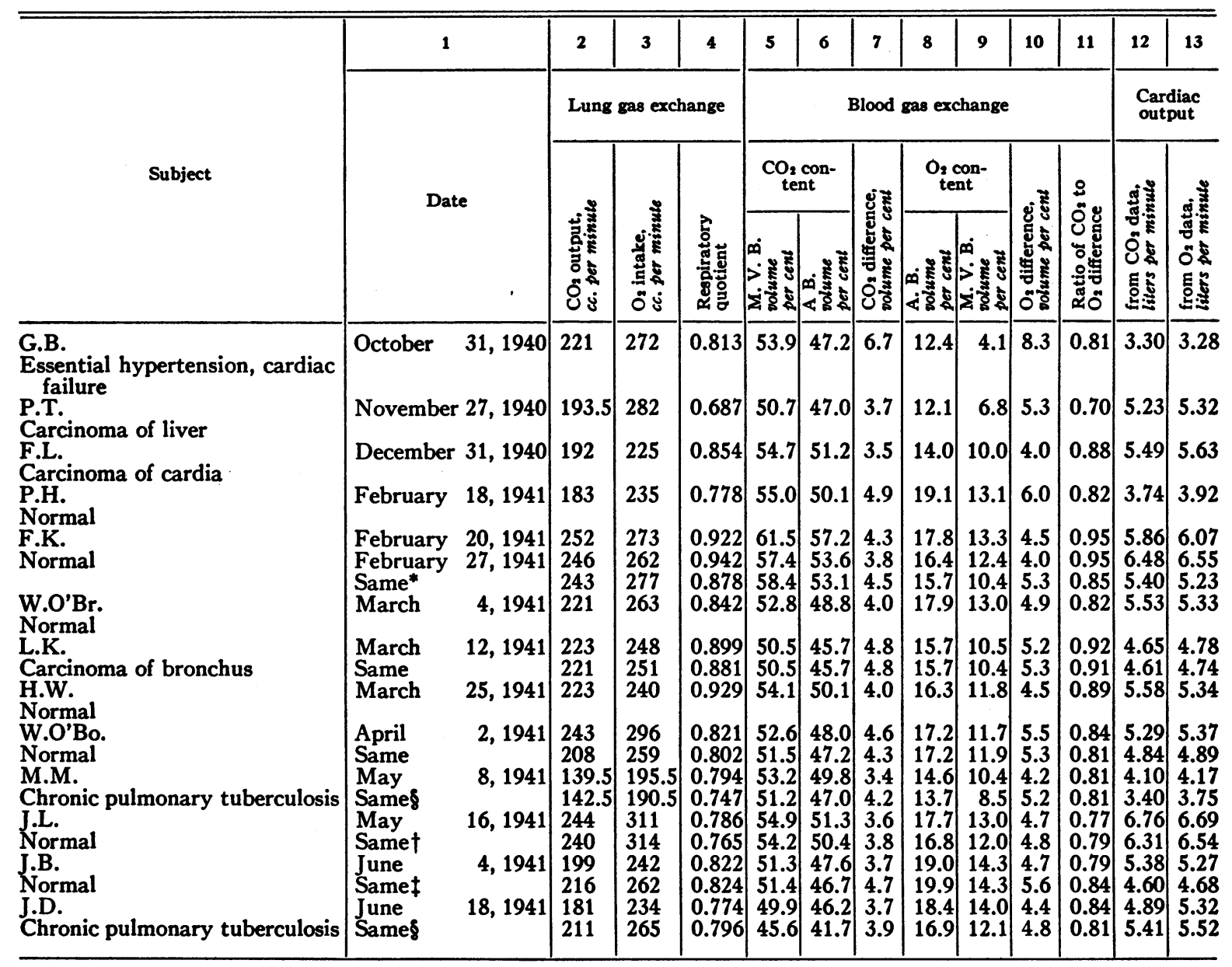

* Four minutes after injection of angiotonin.

$\dagger$ Thirty seconds after injection of angiotonin.

averaged 18.5 per cent larger than by ballistocardiograph, with extremes of +10.6 per cent and +33.5 per cent. This difference between measurements by the two methods is significant for $P=0.05$.

On subjects F. K. and J. B., cardiac output determinations were made before and after the injection of $1 \mathrm{cc}$. of angiotonin. The percentage difference between the values for stroke volume obtained simultaneously by the two methods remained remarkably constant whether or not there were changes in the absolute values of stroke volume due to the action of the drug.

The results of the 16 almost simultaneous pairs of cardiac output determinations have been plotted in Figure 1. The values corresponding to the
$\$$ Three minutes after injection of angiotonin.
\&t the end of prolonged surgical operation.

first 2 subjects in Table II are identified by the open circles. The other 14 points are all above the line of identity. Their distribution is indicative of a very high correlation and a systematic deviation. It can furthermore be inferred that both methods are consistent within themselves. Because of the smallness of the sample, the drawing of a regression line and the calculation of its equation are not justified.

\section{DISCUSSION}

The attempt to compare almost simultaneous cardiac output determinations by the direct Fick method and by the ballistocardiograph resulted in a high proportion of failures for a variety of reasons. Among the successful cases in whom a 
TABLE II

Sixteen simultaneous determinations of stroke volume by the direct Fick method and by the ballistocardiograph in 12 subjects

\begin{tabular}{|c|c|c|c|c|c|}
\hline \multirow{2}{*}{ Subject } & \multirow[b]{2}{*}{ Pulse } & \multicolumn{2}{|c|}{$\begin{array}{l}\text { Stroke } \\
\text { volume }\end{array}$} & \multirow{2}{*}{$\begin{array}{l}\text { Difference } \\
\text { (Direct } \\
\text { Fick)- } \\
\text { (Ballisto- } \\
\text { cardiograph) }\end{array}$} & \multirow{2}{*}{$\begin{array}{l}\text { Ballisto- } \\
\text { cardiograph } \\
\text { record }\end{array}$} \\
\hline & & 趈 & 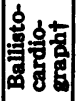 & & \\
\hline L.K. . . . . . . . & $\begin{array}{l}93 \\
108\end{array}$ & $\begin{array}{l}\text { cc. } \\
35.4\end{array}$ & $\begin{array}{c}c c . \\
38.6 \\
59.6\end{array}$ & $\begin{array}{l}c c . \\
-3.2 \\
-16.1\end{array}$ & $\begin{array}{l}\text { Complexes } \\
\text { irregular, } \\
\text { small } \\
\text { Small com- }\end{array}$ \\
\hline 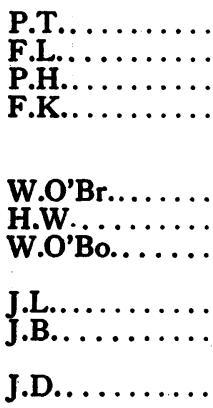 & $\begin{array}{l}112 \\
68 \\
56 \\
61 \\
74 \ddagger \\
688 \\
80 \\
75 \\
64 \\
65 \\
96 \\
65 \ddagger \\
588 \\
84\end{array}$ & $\begin{array}{l}47.2 \\
81.2 \\
68.4 \\
97.8 \\
88.1 \\
78.1 \\
68.0 \\
72.8 \\
83.1 \\
75.0 \\
69.7 \\
81.1 \\
80.7 \\
60.8\end{array}$ & $\begin{array}{l}41.0 \\
73.1 \\
61.6 \\
84.8 \\
73.5 \\
64.8 \\
57.1 \\
63.4 \\
73.1 \\
67.8 \\
52.2 \\
62.2 \\
64.0 \\
49.0\end{array}$ & $\begin{array}{l}+6.2 \\
+8.1 \\
+6.8 \\
+13.0 \\
+14.6 \\
+13.3 \\
+10.9 \\
+9.4 \\
+10.0 \\
+7.2 \\
+17.5 \\
+18.9 \\
+16.7 \\
+11.8\end{array}$ & $\begin{array}{l}\text { Good } \\
\text { Good } \\
\text { Good } \\
\text { Good } \\
\text { Good } \\
\text { Good } \\
\text { Good } \\
\text { Good } \\
\text { Good } \\
\text { Good } \\
\text { Good } \\
\text { Good } \\
\text { Good } \\
\text { Good }\end{array}$ \\
\hline Average. . . . . . & 77.6 & 70.7 & 61.6 & +9.1 & \\
\hline $\begin{array}{l}\text { Average of } 14 \\
\text { with good bal- } \\
\text { listocardiograph } \\
\text { records......... }\end{array}$ & 73.3 & 75.1 & 6.3 .4 & +11.7 & \\
\hline
\end{tabular}

* Stroke volume obtained by averaging figures in two last columns of Table I and dividing by mean pulse rate.

+ Stroke volume obtained by averaging figures of 2 ballistocardiograms taken immediately before and immediately after the direct Fick determination.

¥Before the injection and $\$$ after the injection of angiotonin.

comparison seemed justified, there was a systematic deviation in the results. The following analysis of some of the technical and theoretical considerations involved in the two methods may help to explain these findings.

The direct Fick determination required first the placing of the catheter in the right auricle. In 24 , or 77 per cent, of 31 attempts this procedure was successful. Failures resulted from inability to introduce the catheter into the basilic vein, from obstruction to its course as it was threaded along, or from inability to make it follow the desired venous channels. The apparent harmlessness of the procedure was confirmed, occasional thrombosis of the basilic vein being the only untoward reaction. In more than 50 attempts

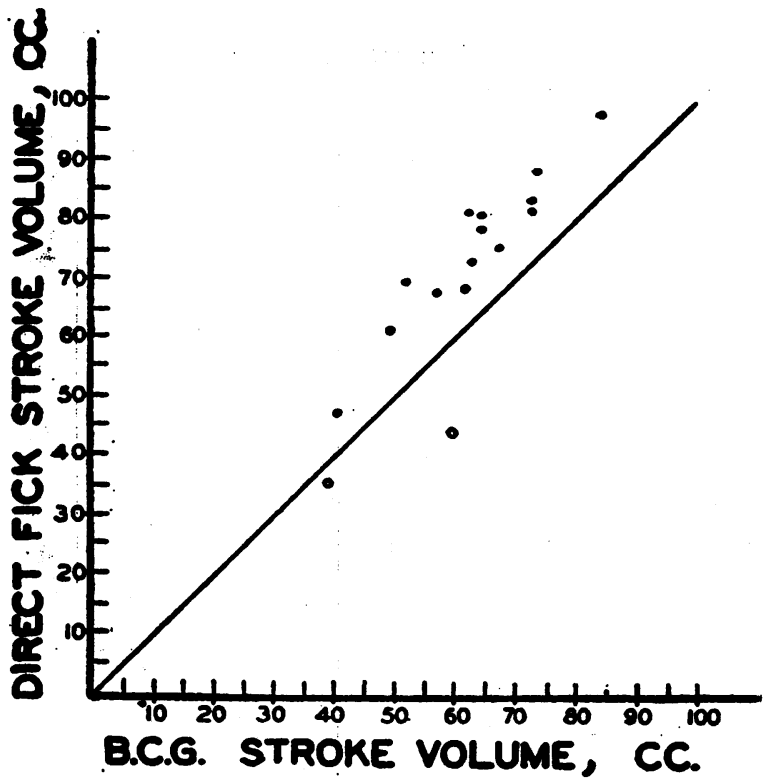

Fig. 1. Sixteen Individual Measurements of Stroke Volume Obtained by the Direct Fick Method Plotted Against the Same Measurements Calculated from Simultaneous BallistocardiograpHS

Open circles represent measurements in 2 subjects with rapid pulse, small and/or irregular ballistic complexes. Straight line is line of identity (see text).

including both those here reported and others to be reported elsewhere, the only physiological responses were a small rise in ventilation and a small degree of sinus bradycardia. Studies now in progress on surgical shock have shown that with the continuous flow of saline maintained at a rate of about 15 drops per minute, the catheter can be kept in position for as long as 3 hours with no inconvenience to the patient.

In the Fick determinations the chief difficulty arose in obtaining simultaneously, and analyzing in duplicate, samples of mixed venous blood, arterial blood, and expired air. In 21, or 44 per cent, of 48 attempts the determinations were satisfactory. The collection of expired air presented no special difficulties. The sampling of arterial blood, following infiltration of the femoral artery with novocaine, was in most cases technically easy and apparently painless. Stimuli arising from the arterial puncture may on occasion have caused momentary increase in the cardiac output, but it is doubtful if this occurred in the selected group of cases in which the pulse rate varied by no more than 3 beats. The sampling of venous 
blood from the right auricle was somewhat complicated by the necessity for washing the catheter free of saline and for taking the strictest precautions against contamination with air. There is also the possibility that samples taken from the right auricle may not always have been representative of thoroughly mixed venous blood. While this possibility has yet to be thoroughly investigated, it is doubtful that it was a source of error in the selected group in which the respiratory quotient obtained from the arteriovenous differences checked reasonably well with the respiratory quotient obtained from analysis of expired air. Certainly the high proportion of failures in performing the direct Fick determination was due mainly to technical difficulties, since error at any point in manipulating the large number of samples required that the entire experiment be discarded.

The determination of cardiac output by the direct Fick method, although difficult, is based on fundamental physiological principles and has checks within itself. The degree of accuracy is therefore thought to be high. Any discrepancy between the results obtained by this method and by the ballistocardiograph may be assumed to be due to error in the latter.
The ballistocardiograms were satisfactory in 16 , or 76 per cent, of the 21 cases in which the Fick determinations were satisfactory. The taking of these tracings was an extremely simple matter provided the optical recording and timing devices functioned properly. The patient was required simply to remain absolutely quiet with his feet firmly against the foot board. Only tracings which were normal in shape were used, since we were interested exclusively in the normal ballistocardiogram. In the comparison of methods several ballistocardiograms taken before and after the direct Fick were not acceptable because the pulse rate varied by more than 3 beats.

Consideration of all possible sources of error related to the ballistocardiograph would require an evaluation of the fundamental assumptions upon which Starr's formulae were based. Assuming, however, for lack of better knowledge, that every other entry from which the formulae were derived is correct, there remains one factor which is open to doubt,-namely, the estimation of the internal cross-section of the aorta. The standard tables, relating aortic cross-section to age and body surface, were compiled by Bazett from data collected by Suter on autopsy material (6). The magnitude of the error introduced by applying

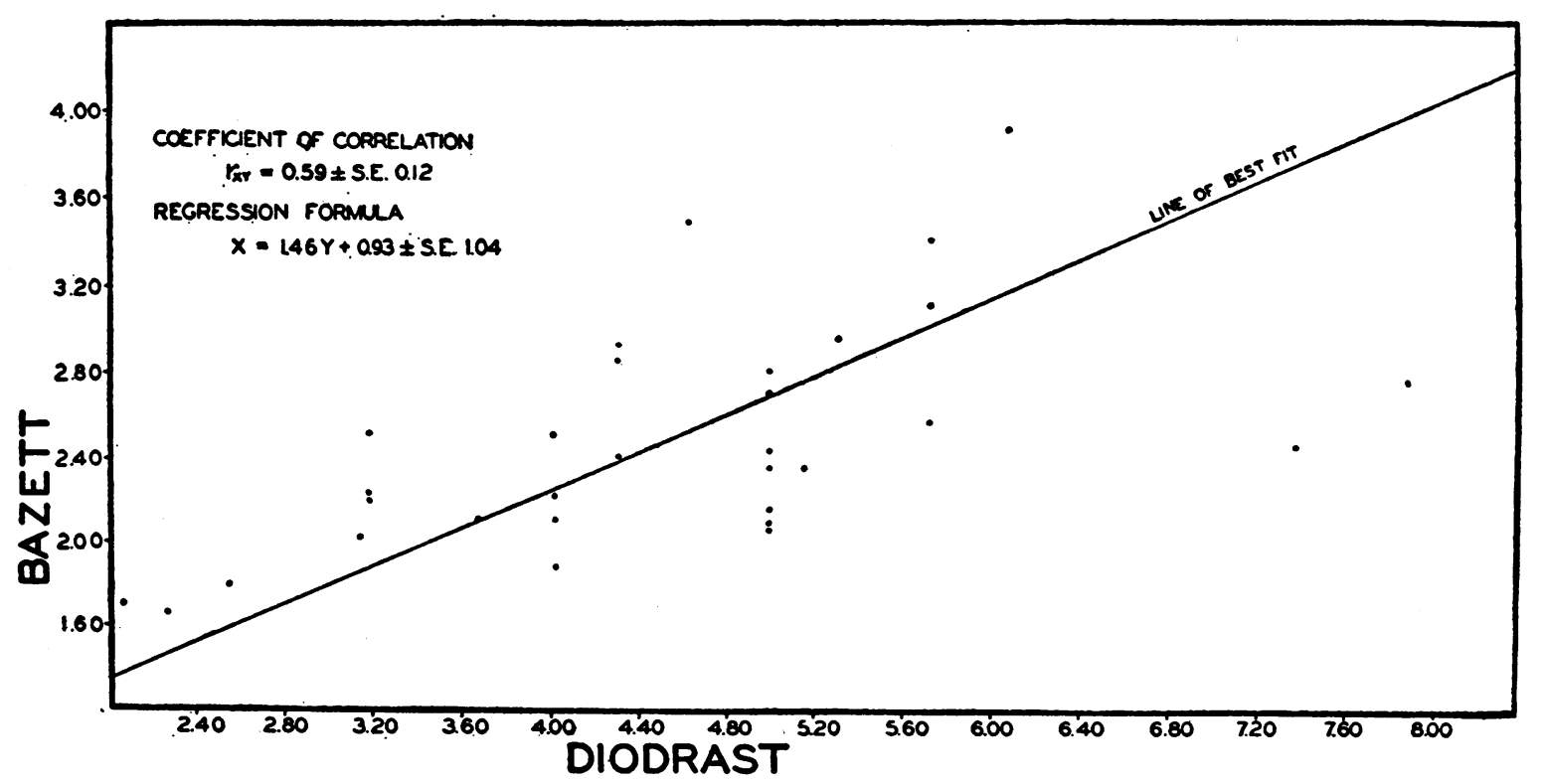

Fig. 2. Internal Cross-section Area of Aorta in sQ. CM. in 31 Normal Subjects

Estimates of this measurement obtained from Bazett's table are compared with measurements calculated from the smallest diameter of the aorta near the aortic ring after diodrast visualization. 
these figures to living subjects is not known, but it can readily be shown that any considerable error in the estimate of aortic cross-section will significantly affect the calculated cardiac output. For example, a 50 per cent error in aortic crosssection (let us say, 3 sq. $\mathrm{cm}$. instead of 2 sq. cm.) will result in a 22 per cent error in stroke volume as calculated by Starr's wave area formula. The error in stroke volume varies with the error in aortic cross-section according to the approximate formula $\frac{d S}{S}=\frac{d A}{2 A}$, where $S=$ stroke volume and $A=$ aortic cross-section.

To test the accuracy of Bazett's figures, the internal diameter of the ascending aorta at its narrowest point was measured directly in 31 normal subjects after visualization of the aorta with diodrast. $^{8}$

The correlation found by Bazett between age, body surface, and aortic cross-section was confirmed, but a more rapid increase in aortic crosssection with increasing body surface was found in each age group. Because of this the diodrast measurements are in general considerably higher than the estimates from Bazett's tables. The values obtained by direct visualization are plotted against estimates obtained from Bazett's data in Figure 3. The correlation coefficient $r x y=0.53$, S.E. $\mp 0.12$ is significant, for $P=$ less than 0.01 . To apply a correction factor to Bazett's figures by using the calculated regression formula is unjustified because of the small size of the sample, the lack of information regarding variations in the size of the aorta on successive diodrast visualizations, and the large error involved in the use of this formula as shown by the standard error.

Since a correction factor could not be applied, the diameter of the aorta was measured by diodrast visualization in 5 of the subjects in whom the cardiac output had been measured by both direct Fick and ballistocardiographic methods. These 5 subjects were representative of the larger group since the average difference between Fick and ballistocardiographic determinations was very nearly the same as the average difference for the entire group of 14 , being 17.3 per cent as opposed to 18.5 per cent. It is significant, there-

${ }^{8}$ The aortic visualization had been performed by Drs. Robb, Steinberg, and Roche, who very kindly placed this material at our disposal.
TABLE III

Comparison between direct Fick and ballistocardiograph stroke volume in 5 subjects. Influence of direct measurement of the aorta (diodrast) in the determination of stroke volume by ballistocardiograph

\begin{tabular}{|c|c|c|c|c|c|c|c|}
\hline \multirow{3}{*}{ Subject } & \multirow{3}{*}{ Age } & \multirow{3}{*}{$\begin{array}{l}\text { Body } \\
\text { surface } \\
\text { area }\end{array}$} & \multirow{2}{*}{\multicolumn{2}{|c|}{$\begin{array}{l}\text { Aortic cross } \\
\text { section area }\end{array}$}} & \multicolumn{3}{|c|}{ Stroke volume } \\
\hline & & & & & \multicolumn{2}{|c|}{$\begin{array}{c}\text { Ballisto- } \\
\text { cardiograph }\end{array}$} & \multirow{2}{*}{$\begin{array}{l}\text { Direct } \\
\text { Fick }\end{array}$} \\
\hline & & & Bazett & $\begin{array}{l}\text { Dio- } \\
\text { drast }\end{array}$ & Bazett & $\begin{array}{l}\text { Dio- } \\
\text { drast }\end{array}$ & \\
\hline $\begin{array}{l}\text { W.O'Bo... } \\
\text { P.H... } \ldots \\
\text { J.L.... } \\
\text { J.D.... } \\
\text { F.L.... }\end{array}$ & $\begin{array}{l}49 \\
52 \\
39 \\
21 \\
61\end{array}$ & \begin{tabular}{|c|} 
sq. $m$. \\
1.88 \\
1.80 \\
1.68 \\
1.79 \\
1.66
\end{tabular} & \begin{tabular}{|l|}
\multicolumn{1}{|r}{ sq. } \\
4.08 \\
4.02 \\
3.02 \\
$2.38^{*}$ \\
4.70
\end{tabular} & $\begin{array}{l}\text { cm. } \\
5.72 \\
5.31 \\
5.73 \\
4.15 \\
5.88\end{array}$ & $\begin{array}{l}70.2 \\
61.6 \\
52.2 \\
49.0 \\
73.1\end{array}$ & $\begin{array}{c}c c . \\
83.2 \\
70.7 \\
71.5 \\
64.3 \\
81.8\end{array}$ & $\begin{array}{l}79.1 \\
68.4 \\
69.7 \\
60.8 \\
81.2\end{array}$ \\
\hline
\end{tabular}

* Estimated on basis of best weight.

fore, that, as shown in Table III, the difference between direct Fick and ballistocardiographic results averaged only 3.5 per cent when the ballistocardiograms were re-calculated using diodrast measurements of the aortas.

It thus appears probable that the use of Bazett's figures for the internal cross-section of the aorta introduces an error into the calculation of cardiac output by Starr's wave area formula, and that in the 5 cases studied, correction of this error by direct measurement of the aortas resulted in good agreement between ballistocardiographic and direct Fick methods.

\section{SUMMARY AND CONCLUSIONS}

1. The accuracy of the ballistocardiographic method of cardiac output determination was tested by comparing it with a method based on the Fick principle.

2. The technique of the direct Fick determination, involving catheterization of the right auricle, was discussed.

3. Fourteen almost simultaneous pairs of cardiac output determinations were compared, in which the following criteria were satisfied: pulse rate varied less than 4 beats; ballistocardiograms were normal in shape, regular, and easily readable; cardiac output calculated separately from oxygen consumption and from carbon dioxide elimination checked closely.

4. Cardiac output as determined by the direct Fick method was found to be larger by 18.5 per cent than the value calculated from the ballisto- 

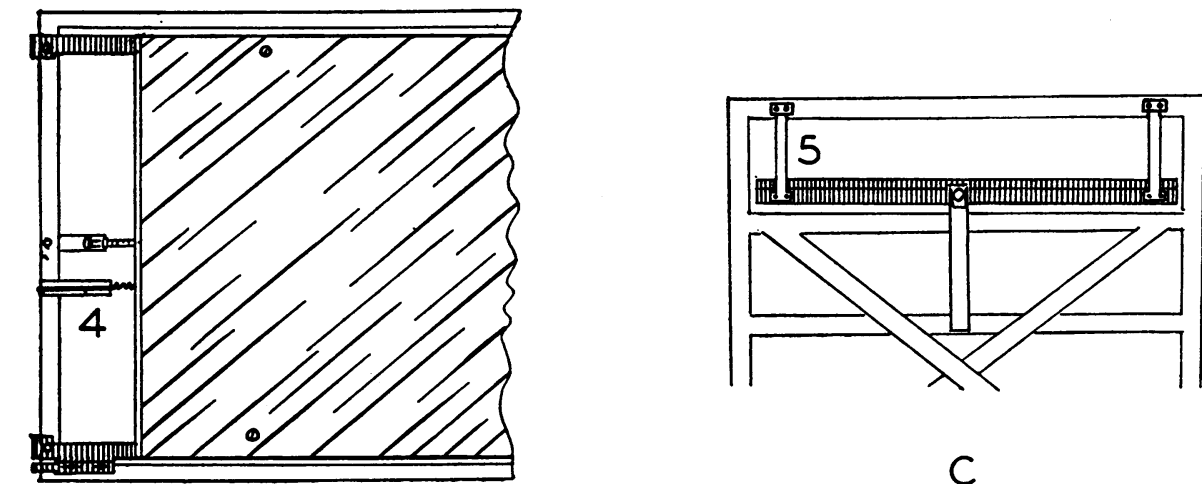

1

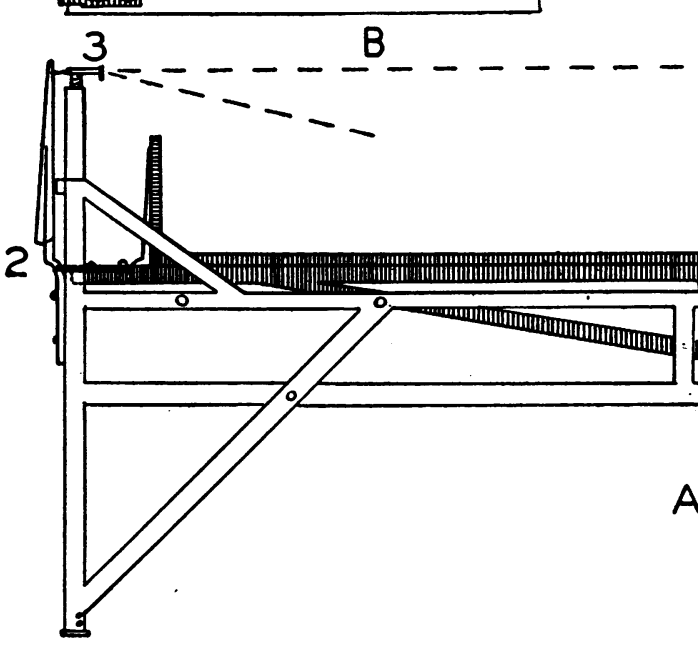

C

FIG. 3.

A. Side view of the ballistograph showing platform (1), driving lever (2), recording lever (3).

B. Top view, showing position of platform with respect to frame and position of calibrating spring (4).

C. End view, showing platform suspended by spring steel strips (5).

D. Cross-section of platform and frame, showing arrangement of strut (9) between frame (8) and platform (7), thereby preventing lateral movement. At either end, the $\% / 8$ inch strut is connected to platform and frame, respectively, by a strip of spring steel $1 / 2$ inch by $1 / 32$ inch.

cardiogram, using Bazett's tables for the internal cross-section of the aorta.

5. Using figures for aortic cross-section obtained by diodrast visualization in 5 cases, cardiac output as calculated from the ballistocardiogram was found to check very closely with the values obtained by the direct Fick method, the average difference being 3.5 per cent.
6. On the basis of these findings, it is suggested that the accuracy of cardiac output determination with the ballistocardiograph may be improved (1) by correcting the calculated value by an amount equal to the average error found experimentally, i.e. 18.5 per cent, or (2) by introducing in the formula a value for internal cross-section of the aorta based on diodrast visualization. 


\title{
APPENDIX
}

\section{THE DESIGN OF THE BALLISTOCARDIOGRAPH}

\author{
By DUGALD E. S. BROWN \\ (Department of Physiology, New York University College of Medicine)
}

The design of the ballistocardiograph follows, in general, the principles of that of Isaac Starr (2). The major problem faced in a portable model is the elimination of distortion and vibrations arising from faulty design. The short suspension elements and the position of the driving lever and optical recording units were selected as being most suitable for the purpose. Damping of the platform would greatly improve the records but does not appear necessary at the present time.

The framework throughout is of angle iron, $11 / 4$ inches wide and $1 / 8$ inch thick, reinforced with bands $11 / 4$ inches by $1 / 8$ inch. The platform is covered with $7 / 8$ inch plywood and, if desired, may be covered with a sponge rubber mat 1 inch in thickness.

The platform is suspended by four strips of spring steel, 5 inches long, $6 / 8$ inch wide, and $1 / 32$ inch thick. It is fitted with a locking device at the foot to immobilize the platform when necessary. Lateral stabilization of the platform is obtained by struts (Figure 1, D, 6) of the type employed by Starr.

The driving lever (Figure 1, A, 2) is a strip of tool steel, $51 / 2$ inches by $3 / 4$ and $1 / 4$ inch in thickness. The platform rests against the lever $1 / 2$ inch from the fulcrum through a knife-edge strip of tool steel. An aluminum extension, braced to eliminate secondary vibrations, provides a light extension of the driving lever to its attachment to the recording lever (Figure 1, A, 3).

The recording lever, of the torsion wire type, provides a positive connection to the driving lever at all times through a light piece of chain. The mirror is mounted rigidly on the torsion band to eliminate secondary free vibrations. It is front surfaced with aluminum and has a focal length of $0.25 \mathrm{D}$.

The lamp, mounted on the head of the bed, has a 75 watt projection bulb as a light source, a short focus condensing lens and an adjustable slit. With a $0.25 \mathrm{D}$ mirror, the image of the slit comes to a focus 0.5 meters behind the lamp.

For purposes of calibration, a spring is provided which is attached between the frame and the platform at 4 (Figure 1, B). Extension of the spring two centimeters exerts a force of 1000 grams upon the platform.
The period of the platform under a given load depends on the length of the suspension strips, the elasticity of the driving lever, and the elasticity of the recording lever. If a shorter period (greater frequency) is desired, the simplest procedure is to increase the thickness of the driving lever. Some amplitude will be lost, but this can easily be corrected for by moving the camera further from the mirror. In use, the bed must rest directly on a solid floor if the free period of $\mathbf{1 5}$ per second is to be retained. Best results are obtained when the bed is placed close to an outside wall at right angles to the axis of vibration of the floor, if such exists.

\section{BIBLIOGRAPHY}

1. Starr, I., and Schroeder, H. A., Ballistocardiogram. II. Normal standards, abnormalities commonly found in disease of the heart and circulation, and their significance. J. Clin. Invest., 1940, 19, 437.

2. Starr, I., Rawson, A. J., Schroeder, H. A., and Joseph, N. R., Studies on the estimation of cardiac output in man, and of abnormalities in cardiac function, from the heart's recoil and the blood's impacts; the ballistocardiogram. Am. J. Physiol., 1939, 127, 1.

3. Starr, I., Gamble, C. J., Marjolies, A., Donal, J. S., Jr., and Eagle, E., A clinical study of the action of ten commonly used drugs on cardiac output, work and size; on respiration, on metabolic rate, and on the electrocardiogram. J. Clin. Invest., 1937, 16, 799.

4. Grollman, A., The Cardiac Output of Man in Health and Disease. Monograph. Charles C. Thomas, Baltimore, 1932.

5. Cournand, A., and Ranges, H. A., Catheterization of the right auricle in man. Proc. Soc. Exper. Biol. and Med., 1941, 46, 462.

6. Bazett, H. C., Cotton, F. S., Laplace, L. B., and Scott, J. C., The calculation of cardiac output and effective peripheral resistance from blood pressure measurements, with an appendix on the size of the aorta in man. Am. J. Physiol., 1935, 113, 312. 